\title{
Growth and growth hormone secretion in children with cancer treated with chemotherapy
}

Juan Román, MD, PhD, Carmen J Villaizán, MD, Jesús García-Foncillas, MD, Javier Salvador, MD, $\mathrm{PhD}$, and Luis Sierrasesúmaga, $\mathrm{MD}, \mathrm{PhD}$

From the Departments of Pediatric Oncology and Endocrinology, Clínica Universitaria de Navarra, Facultad de Medicina, Universidad de Navarra, Pamplona, Spain.

Supported in part by a grant from the Navarra Government.

Reprint requests: Juan Román, MD, PhD, Department of Pediatric Oncology, Clínica Universitaria de Navarra, Universidad de Navarra, Pio XII s/n, Apartado 192, 31080 Pamplona (Navarra), Spain.

\section{ABSTRACT}

Objective: To evaluate the effect of chemotherapy on growth and growth hormone (GH) secretion.

Methods: We analyzed growth and GH secretion in 60 children in complete remission after treatment by chemotherapy and surgery for malignant solid tumors. None of them received cranial radiotherapy. Growth hormone reserve was assessed by at least two stimulation tests (clonidine, L-dopa, growth hormone-releasing hormone). In 12 children the reserve of GH pretreatment was also evaluated.

Results: Growth hormone deficiency (GHD) was observed in 27 of 60 patients (45\%). At diagnosis, mean standing height was $+0.23 \pm 0.11$ standard deviation score (SDS) in the GHD group and $+0.16 \pm 0.10$ SDS in the non-GHD group. Alter chemotherapy, mean standing height in the GHD group was $-0.28 \pm 0.15$ SDS and $-0.14 \pm 0.11$ in the non-GHD group $(\mathrm{p}<0.05)$, and the growth rate was $+0.13 \pm 0.07$ SDS in the GHD group and $+0.22 \pm 0.18$ SDS in the non-GHD group. For a mean follow-up of 30 months, the mean standing height was $-0.46 \pm 0.29$ SDS in the GHD group and $-0.24 \pm$ 0.16 SDS for the non-GHD group $(\mathrm{p}<0.05)$, and the growth rate was $-0.27 \pm 0.19$ SDS in the GHD group and $-0.16 \pm 0.12$ SDS in the non-GHD group $(p<0.05)$. The GH response to clonidine was significantly less than that found with the other stimuli.

There was correlation between the dose intensity of some drugs and the subsequent GH response to stimulation tests. The GHD group was found to have received significantly higher doses of actinomycin D than the non-GHD group $(p<0.05)$. Growth impairment and GHD were not found to be correlated with duration of treatment and follow-up, tumor type, sex, or age.

Conclusions: Chemotherapy as the sole form of treatment in children with cancer interferes with growth. The observed impairment of growth depends, at least in part, on a GHD related to chemotherapy. The growth rate in conjunction with the GH response to clonidine provides a sensitive measure of GHD associated with chemotherapy. 


\begin{tabular}{l}
\hline ABBREVIATIONS \\
AUC Area under the curve \\
GH Growth hormone \\
GHD Growth hormone deficiency \\
GHRH Growth hormone-releasing hormona \\
HT-P Hypothalamic-pituitary axis \\
IGF lnsulin growth factor \\
SDS Standard deviation score \\
\hline
\end{tabular}

\section{INTRODUCTION}

The prognosis of children with cancer has improved significantly in recent years as a result of new therapeutic modalities. ${ }^{1}$ Unfortunately, some of these children will have late effects of therapy, including those involving the endocrine system and related to growth.

Recently we observed in a group of 25 children with osteosarcoma that chemotherapy used as the only form of treatment interfered with growth, probably as a result of a growth hormone deficiency caused by the chemotherapy. ${ }^{2}$ In this preliminary work we did not evaluate the pretreatment reserve of growth hormone and thus cannot Mame chemotherapy for the GHD observed because we cannot be certain the patients were not $\mathrm{GH}$ deficient before therapy. For this reason a prospective study was designed in which the reserve of GH was evaluated before and after treatment while we continued to study the growth and secretion of $\mathrm{GH}$ in a greater number of patients with different malignancies, who were treated with other schedules of polychemotherapy. To our knowledge, this is the first prospective study that analyzes both growth and GH secretion in children treated exclusively by chemotherapy. In addition, in the previous report the stimuli for GH secretion (clonidine and L-dopa) assessed the hypothalamicpituitary axis by acting at the hypothalamic level, which did not allow us to discern between possible damage to the hypothalamus, the pituitary, or both areas. ${ }^{2}$ In this article we study the HT-P axis by use of stimuli that act at both the hypothalamic level (clonidine and L-dopa) and the pituitary level (growth hormone-releasing hormone). Other aims of the study were the possible identification of risk factors (duration of treatment and follow-up, dose intensity of chemotherapy, type of tumor, sex, or age at diagnosis) for increased susceptibility to alterations in growth and GH secretion.

\section{METHODS}

Sixty consecutive children with histologically proved malignant solid tumors treated between the years 1984 and 1994 were induded in this study. Informed consent was obtained from all patients and their parents before the study.

The subjects were divided into two groups. Group I (retrospective group) comprised 48 patients (26 male subjects) who had received chemotherapy before the study. The 25 patients with osteosarcoma previously described ${ }^{2}$ were included in this group. Mean age was 13.8 years (range, 4.2 to 19.8 years). The histologic type and primary location of 
the tumors of these patients were as follows: 31 cases of osteosarcoma (19 femur, 9 tibia, 1 fíbula, 1 ulna, 1 hip), 6 cases of Ewing sarcoma [1 femur, 4 tibia, 1 clavicula], 3 cases of rhabdomyosarcoma (1 bladder, 1 abdominal wall, 1 pelvis), 3 cases of Hodgkin disease, 4 cases of non-Hodgkin lymphoma; and 1 case of Wilms tumor (kidney). Group II (prospective group) comprised 12 patients (7 male subjects) who had not received chemotherapy before the study. Mean age was 12.4 years (range 4.5 to 17 years). The histologic type and primary location of the tumors of these patients were as follows: 10 cases of osteosarcoma ( 5 femur, 4 tibia, 1 humerus), 2 cases of Ewing sarcoma (1 fíbula, 1 paravertebral).

The treatment of these patients consisted of chemotherapy and surgery. Intraoperative radiotherapy over the tumoral bed was used in $60 \%$ of the cases of osteosarcoma and $25 \%$ of the cases of Ewing sarcoma. External radiotherapy localized to the tumor site was used in all cases of Ewing sarcoma, Hodgkin disease, and Wilms tumor, and 33\% of the cases of rhabdomyosarcoma. Cranial radiotherapy and intrathecal chemotherapy were not used in any of the cases.

The chemotherapy regimen used, according to tumor type, is provided in Table I. In 14 patients with osteosarcoma, cisplatin was administered with or totally replaced by carboplatin.

For each patient the dose intensity of chemotherapy was calculated as the total amount of each drug administered per unit of body surface and per unit of time $\left(\mathrm{mg} / \mathrm{m}^{2}\right.$ per week) at the end of therapy. Mean duration of treatment was $11.8 \pm 3.4$ months. Chemotherapy of all patients was completed before hormonal study; the mean duration of this interval was $14.9 \pm 1.8$ months (standard error of the mean).

For patients in both groups I and II, growth data at the moment of diagnosis, on completion of chemotherapy, and at the start of the hormonal study were obtained retrospectively from hospital records. Height was measured on a wall-mounted Harpenden stadiometer by a trained observer on each clinic visit. The height of patients whose primary tumor was located in the lower limbs was measured carefully, taking into account the length of the healthy limb. Growth velocity was calculated by height determinations obtained during follow-up. Four patients who had received radiotherapy to the vertebral column were excluded from the auxologic study.

Data were compared with the growth standards of Tanner et al. ${ }^{3}$ Results were reported as standard deviation scores (SDS $=[a-\bar{a}]: S D)$ to allow for comparison of patients of different sex and age.

Pubertal status was assessed clinically by the method of Tanner. ${ }^{4}$ Testicular volumes were estimated by comparison with the Prader orchidometer. ${ }^{5}$ Bone age was evaluated according to the Tanner-Whitehouse 2 method. ${ }^{6}$ Nine girls with bone age greater than 14 years and 9 boys with bone age greater than 16 years were excluded from auxologic evaluation.

For all patients (groups I and II), after a posttreatment interval we assessed the GH response to at least two of the following stimuli: clonidine $\left(0.15 \mathrm{mg} / \mathrm{m}^{2}\right.$ orally, L-dopa (300 $\mathrm{mg} / \mathrm{m}^{2}$ orally), and GHRH (1-2 $\mu \mathrm{g} / \mathrm{kg}$ intravenously). Each stimulation test was performed at $8 \mathrm{AM}$ on different days. The combination of clonidine and L-dopa was 
given to 22 patients, clonidine and GHRH to 32 patients, and clonidine, L-dopa, and GHRH to 6 patients. Growth hormone deficiency was diagnosed as a failure to achieve a peak $\mathrm{GH}$ response of $10 \mathrm{ng} / \mathrm{ml}$ to at least one of the provocative tests. We determined the area under the curve for all patients on the basis of the values obtained in the provocative tests. The AUC was calculated with the trapezoidal solution. All patients were also tested for basal insulinlike growth factor I levels. Growth hormone levels were measured by means of a double-monoclonal immunoradiometric assay with a detection limit of $0.1 \mathrm{ng} / \mathrm{ml}$ (human growth hormone "COATRIA", Biomérieux, Marcy l'Etoile, France). Intraassay variation was $5.2 \%$ to $2.1 \%$ at $\mathrm{GH}$ levels between 1.05 and $43.5 \mathrm{ng} / \mathrm{ml}$. Interassay variation was $6 \%$ at a $\mathrm{GH}$ level of $1.1 \mathrm{ng} / \mathrm{ml}$ and $3.7 \%$ at 41.8 $\mathrm{ng} / \mathrm{ml}$. AH samples from one child were measured in the same assay, and all samples were measured in duplicate. The IGF-I levels were also measured with a doublemonoclonal immunoradiometric assay with a detection limit of $0.001 \mathrm{U} / \mathrm{ml}$ (Diagnostic Systems Laboratories Inc., Webster, Tex.). The assay was performed after an acid extraction step in which IGF-I is separated from its binding protein in serum. Intraassay variation was $7.2 \%$ to $4.9 \%$ at IGF-I levels between 0.07 and $0.65 \mathrm{U} / \mathrm{rnl}$. Interassay variation was $7.1 \%$ at an IGF-I level of $0.02 \mathrm{U} / \mathrm{ml}$ and $10.1 \%$ at $0.35 \mathrm{U} / \mathrm{ml}$. All samples from one child were measured in the same assay, and all samples were measured in duplicate.

For all patients in group II the same hormonal study as described aboye was undertaken before the start of treatment for cancer. For these pretreatment tests, all patients were given clonidine and GHRH as stimuli to GH release.

\section{Statistical Analysis}

Results are expressed as mean \pm SD unless otherwise noted. Comparisons between groups were analyzed by the Wilcoxon rank-sum test. Chi-square test was used to compare the differences in the distribution of the patients characteristics. The $p$ values for all tests are two tailed. Correlation was assessed with simple and multiple linear regression. A $p$ value of less than 0.05 was considered statistically significant. Data from this investigation were analyzed with the SPSS program for Windows, version 6.0 (SPSS Inc., Chicago, Ill.) and BMDP Dynamic ver-sion 7.0 (Cork, Ireland) packages.

\section{RESULTS}

\section{Auxologic Study}

Data from both the prospective and retrospective groups was pooled because all anthropometric data were available for all patients in both groups at diagnosis, at the end of treatment, and when the study was performed.

When analyzed in terms of height percentiles, the data demonstrate a statistically significant reduction in the height percentiles of patients during treatment $(p<0.05)$. The reduction in the height percentiles was even more significant during the posttreatment interval $(\mathrm{p}<0.01)$ (Figure). 
When analyzed in terms of SDS, the data demonstrated a statistically significant relative reduction in height during treatment $(0.19 \pm 0.10$ vs $-0.21 \pm 0.14$ SDS, $\mathrm{p}<0.05)$; this reduction continued throughout the posttreatment interval. For a mean follow-up of $30 \pm$ 4 months from the end of treatment, we again observed a statistically significant reduction $(\mathrm{p}<0.05)$ in height and growth rate with respect to that at the end of treatment $(-0.21 \pm 0.14$ vs $-0.35 \pm 0.23$ SDS and $0.18 \pm 0.13$ vs $-0.22 \pm 0.15$ SDS, respectively).

\section{Hormonal Study}

\section{Prospective goup}

All patients had adequate pretreatment response of GH. The GH response before and after treatment and the statistical analysis of the data are listed in Table II. The percentage of patients who had an adequate GH response after stimulation (percentage of response) with clonidine or GHRH before treatment was significantly higher than that obtained after treatment ( $73 \%$ vs $8 \%$ and $91 \%$ vs $42 \%$, respectively; $p<0.001$ for both stimuli). All the patients had normal serum levels of IGF-I before treatment; three patients had subnormal levels of IGF-I after treatment.

\section{Prospective and retrospective groups}

Data from both the prospective and retrospective groups were pooled to investigate the relationship between the results of the study of the HT-P axis and other variables such as dose intensity of chemotherapy administered, duration of treatment, duration of the posttreatment interval, age, sex, and so on.

For $45 \%$ of all patients (20 cases of osteosarcoma and 7 nonosteosarcoma), the GH response after stimulation was subnormal. A comparative statistical analysis of GH response in GH-deficient and non-GH-deficient patients according to stimulus used is given in Table III.

In 20 of the 60 patients the serum IGFI level was below the normal range; 12 of the 20 patients were $\mathrm{GH}$ deficient, and 8 were not $\mathrm{GH}$ deficient.

In 9 patients bone age was retarded 1 year or more in comparison with the TannerWhitehouse standards; 5 of these patients were GH deficient and 4 were not. Bone age ranged from retarded 33 months to advanced 2 months.

Pubertal development was within the normal range for all patients. All girls at Tanner stages 3 and 4 had experienced menarche with mean age at menarche of 12.4 years. Boys had testicular volume in accordance with their pubertal stage and there was normal development of secondary sexual characteristics in older patients.

\section{Relationships Between Auxologie and Hormonal Studies}

We looked for a correlation between auxologic and hormonal data in the GHD and the non-GHD groups. At diagnosis, mean standing height was $+0.23 \pm 0.11$ SDS in the GHD group and $+0.16 \pm 0.10$ SDS in the non-GHD group. At the end of treatment, mean standing height was $-0.28 \pm 0.15$ SDS in the GHD group and $-0.14 \pm 0.11$ SDS in the non-GHD group $(\mathrm{p}<0.05)$. For a mean follow-up period of 30 months from the 
end of treatment, the mean standing height was $-0.46- \pm 0.29$ SDS in the GHD group and $-0.24 \pm 0.16$ SDS in the non-GHD group $(\mathrm{p}<0.05)$. Growth rate at the end treatment was $+0.13 \pm 0.07$ SDS in the GHD group and $+0.22 \pm 0.18$ SDS in the nonGHD group. For a mean follow-up period of 30 months from the end of treatment, growth rate was significantly different between the GHD and the non-GHD groups $(-0.27 \pm 0.19$ vs $-0.16 \pm 0.12$ SDS, $\mathrm{p}<0.05)$ (Table IV).

\section{Relationships Between Oncologic/Auxologic Hormonal Data}

There was no relationship between duration of treatment, duration of posttreatment interval, type of tumor, dose intensity of chemotherapy, sex, or age at diagnosis and either of the auxologic parameters (height and growth rate). There was no relationship found between duration of treatment, duration of posttreatment interval, type of tumor, sex, or age at diagnosis and the existence or absence of GHD. There was a tendency toward a greater incidence of GHD in patients who received chemotherapy at a younger age, although this was not statistically significant $(p=0.07)$. However, a significant correlation was observed between age at diagnosis and maximum peak and AUC of GH after stimulation with L-dopa ( $p=0.01$ and $p=0.02$, respectively).

There was a statistically significant rela-tionship between existence of GHD and dose intensity of actinomycin D $(p<0.05)$. No relationship was observed between GHD and the dose intensity of other chemotherapeutic agents. There was a significant correlation between dose intensity of carboplatin and maximum peak and AUC of GH after stimulation with clonidine ( $p=0.02$ and $p=0.03$, respectively). Statistically significant correlation between dose intensity of actino-mycin D and maximum peak and AUC of $\mathrm{GH}$ after stimulation with L-dopa was also observed $(p=0.04)$.

\section{DISCUSSION}

\section{Chemotherapy and Growth}

The influence of chemotherapy, when used as the only form of treatment for cancer, on growth is poorly understood and has been studied in patients with hematologic neoplasms (leukemia or lymphoma). Furthermore, the issue has almost always been approached indirectly because, in the majority of cases, chemotherapy is an integral part of a combined treatment program with radiotherapy, ${ }^{7-22}$ and for this reason the results of such studies are not entirely comparable with ours. These studies attribute a negative influence of chemotherapy on growth on the basis of the following observations: patients treated with longer or more intensive courses of chemotherapy exhibit less growth than those treated with shorter or less intense regimens, ${ }^{10,15,16,18}$ and patients treated with both radiotherapy and chemotherapy have less growth than those treated exclusively with radiotherapy. ${ }^{17}$

In most of these studies, an influence of chemotherapy on growth parameters (height/growth rate) was observed, whether as a reduction in the growth rate during chemotherapy followed by catchup growth ${ }^{9,12-14,20-22}$ or in a "chronic" form with absent or reduced subsequent recovery. ${ }^{7,10,15-18}$ Some studies have found no significant 
influence of chemotherapy on grovvth. ${ }^{8,11,19}$ It is probable that differences in drug regimens may account for reported variations in the incidence and severity of growth retardation in patients treated with chemotherapy ${ }^{12,13,20}$

In our study, as in some others, ${ }^{12}$ growth parameters (height/growth rate) were not correlated with duration of treatment or intensity of chemotherapy. However, some authors have indeed observed such correlation. ${ }^{15,16,18}$ We did not observe relationships between duration of follow-up, type of tumor, sex, age at diagnosis, and abovementioned parameters. Other authors have observed greater growth impairments in the youngest patients ${ }^{10,18}$ and in girls. ${ }^{18}$

\section{Chemotherapy and Seeretion of Growth Hormone}

Given the previously demonstrated negative influence of chemotherapy on growth and having eliminated the most common causes of short stature in the child population (malabsorption syndromes, infections, diseases of the kidney, liver, blood), we decided to look for a hormonal explanation.

The only studies of GH secretion in children treated exclusively with chemotherapy are limited to hematologic neoplasms, ${ }^{19,23,24}$ and more recently to children who received chemotherapy without total body irradiation in preparation for bone marrow transplantation as treatment for hematologic neoplasms and other nontumoral illnesses (aplastic anemia, immunodeficiency syndromes, and so on). ${ }^{19,25-27}$ The majority, but not all, of these studies found that chemotherapy did not affect GH secretion. Voorhess et at. $^{23}$ found subnormal response of GH after stimulation with arginine and insulin in 5 of 60 patients who had been treated with chemotherapy for acute lymphoblastic leukemia although these patients had also received intrathecal methotrexate therapy as prophylaxis for the central nervous system.

According to the results of our prospective study, chemotherapy used as the only form of treatment in children with cancer significantly diminishes secretion of $\mathrm{GH}$ provoking GHD in a significant percentage of patients.

Neither sex nor age at diagnosis represented risk factors for GHD in our patients, although we did observe a tendency toward a greater incidence of GHD in patients who received chemotherapy at a younger age. Kirk et al. ${ }^{10}$ observed an in-crease in the incidence of GHD in boys relative to girls.

The posttreatment levels of IGF-I were diminished in 20 of the $60(33 \%)$ children in our study. In this respect our results coincide with those of other studies ${ }^{2,16,19}$ and corroborate the theory suggested by some authors ${ }^{28,29}$ that chemotherapy reduces IGF-I concentrations in the circula-tion. This theory is further supported by Thun-Hohenstein et al., ${ }^{16}$ who reported that $75 \%$ of the cases of IGF-I deficit in their study were associated with patients who had received more intensive chemotherapy. As suggested by Rappaport and Brauner ${ }^{28}$ and supported by Berry et al., ${ }^{9}$ it would not be surprising to find that plasma concentrations of IGF-I decrease during chemotherapy. In our study we did not measure IGF-I levels during or immediately after treatment and thus do not know how these levels changed over time. Malnutrifion may also contribute to reduced IGF-I levels in both groups. Another possibility in the non-GHD group is the 
development of a GH neurosecretory dysfunction, which would explain the coexistente of normal GH response to stimulation, poor growth in many patients, and low IGF-I values. $^{2}$ Increased levels of IGF-I were not detected in any of our patients; this finding suggests that resistance or an altered sensitivity of tissue receptors to growth factors does not develop in patients treated by chemotherapy. ${ }^{24}$

\section{Physiopathology of Growth Impairment after Chemotherapy}

The mechanism by which chemotherapy interferes with growth is not fully un-derstood. A reduction in the growth rate of children during oncologic treatment is a predictable and well-demonstrated fact. ${ }^{9,12-15,18,21,24}$ Various explanations have been proposed including (1) the disease process itself, (2) an increase in nutritive requirements, (3) malnutrition during treatment, (4) infections, (5) vomiting, (6) the treatment (chemotherapy, radiothera-py, corticoids) and, (7) combinations of the aboye factors. However, a persistent reduction in growth rate after cessation of chemotherapy is difficult to explain ${ }^{2,10,15-18}$ except in cases in which the tumor or the treatment produce or provoke important late effects. Studies to date attribute this persistent reduction in growth rate to (1) prolonged treatment with corticoids, (2) radiotherapy/chemo-therapy synergism, (3) GHD as a result of cranial radiotherapy, (4) intensity and duration of chemotherapy, or (5) reduced peripheral tissue response to growth factors.*

On the basis of the results of our prospecfive study, we suggest that GHD related to chemotherapy should be considered as a further cause of persistent re-duction in growth rate, especially because we have demonstrated that patients with GHD grow significantly less than those without GHD. Other authors have found a similar relationship between reduced growth and GHD, ${ }^{7}$ although still others have found no such relationship. ${ }^{16,23}$ Furthermore, in corroboration with Kirk et al, ${ }^{10}$ we did not detect GHD in all patients with growth impairment.

The GHD could be related to a toxic effect of chemotherapy on the HT-P axis, especially in drugs such as carboplatin that are known to cross the blood-brain barrier. ${ }^{31}$ We believe that this possible selective toxic effect of chemotherapy on the HT-P axis is related more to individual susceptibility than the other parameters, given that, as we have pointed out, we did not find any relationship between GHD and either duration of treatment or duration of posttreatment interval. Furthermore, there is no apparent relationship between cumulative dose of "toxin" and toxic effect except that related to carboplatin and actinomycin-D. In this respect our results coincide with those of other authors. ${ }^{16}$

Clonidine and L-dopa stimulate GH secretion by acting at the hypothalamic level. ${ }^{32-34}$ L-Dopa, like exogenous GHRH, also stimulates GH secretion by acting at the pituitary level. $^{35}$

Given the mechanisms of stimulation of GH secretion, we might hypothesize that chemotherapy damages the pituitary. This hypothesis is supported by the reduced posttreatment response to clonidine and GHRH in the prospective group. Alternatively, chemotherapy might damage the hypothalamus, which is supported by the fact that in the prospective group the most pronounced reduction in response to stimulation occurred with clonidine (Table II). Similarly, in the non-GHD group the GH response 
(maximum peak and AUC) was smaller after stimulation with clonidine than after stimulation with GHRH and L-dopa (Table III). Damage to the hypothalamus is further suggested by the fact that in the GHD groups the reduction in response to clonidine in ternas of AUC was relatively greater than the reduction in response to L-dopa and especially GHRH (Table III).

The possibility of functional somatotroph cell impairment related to preexisting hypothalamic dysfunction in the cause of GHD also needs to be considered, because a reduced GH response to GHRH was found in the group with GHD. However, direct pituitary Damage, which might be related to a certain cytostatic dose or individual tolerance to chemotherapy, cannot be ruled out.

The fact that some patients without GHD patients had reduced growth rate with subsequent recovery could indicate that some patients have a transient functional impairment as a result of chernatherapy but later recover.

The alterations resulting from chemotherapy in the secretion of GH appear to be similar to those resulting from cranial radiotherapy, which is known to cause a primary lesion in the hypothalamus. ${ }^{28,36}$ As could be the case with chemotherapy, high doses of radiotherapy produce an effect in both the hypothalamus and the pituitary. ${ }^{28}$

We conclude that chemotherapy at high doses, when used in children as the only form of treatment for cancer, interferes with growth during and after treatment. Furthermore, such chemotherapy when used in children as the only form of treatment for cancer provokes GHD. Given that patients with GHD grow significantly less than those without GHD, we believe that the observed impairment of growth of these children depends, at least in part, on a GHD. This GHD resulting from chemotherapy could be related to an alteration in the hypothalamus, although it is not possible to rule out an alteration in the pituitary. In this study we found no factors related to treatment (duration of treatment, duration of posttreatment interval), oncology (type of tumor), or demographics (sex, age at diagnosis) that would allow prediction of the appearance of a GHD or an impairment of growth. Individual susceptibility and the dose intensity of some drugs probably explain the appearance of these alterations in certain patients. Finally, given that the GH response to clonidine in the non-GHD group was markedly reduced relative to the response to the other stimuli, we believe that a diminished growth rate in conjunction with a reduced response to clonidine is a sensitive measure of GHD associated with chemotherapy. These measurements should be taken in the follow-up of patients for the detection of any alteration in growth so that treatment can be considered as soon as possible.

\section{REFERENCES}

1. Miller RW, Young JL, Novakovic B. Childhood cancer. Cancer 1995;75(suppl 1):395-405.

2. Román J, Villaizán CJ, García-Foncillas J, Azcona C, Salvador J, Sierrasesúmaga L. Chemotherapy-induced growth hormone deficiency in children with cancer. Med Pediatr Oncol 1995;25:90-5. 
3. Tanner JM, Whitehouse RE, Takaishi M. Standards from birth to maturity for height, weight, height velocity and weight velocity: British children, 1965. Arch Dis Child 1966;41:613-35.

4. Tanner JM. Growth at adolescence. Oxford: Blackwell Scientific, 1962.

5. Zachmann M, Prader A, Kind HP, Hafliger H, Budliger H. Testicular volumes during adolescence: cross sectional and longitudinal studies. Hely Paediatr Acta 1974;29:6172.

6. Tanner JM, Whitehouse RH, Marshall WA, Healy MJR, Goldstein H. Assessment of skeletal maturity and prediction of adult height (TW2 method). New York: Academic Press; 1975.

7. Bajorunas DR, Ghavimi F, Jereb B, Sonenberg M. Endocrine sequelae of antineoplastic therapy in childhood head and neck malignancies. J Clin Endocrino' Metab 1980;50:329-35.

8. Wells R, Foster M, D'Ercole AJ, McMillan C. The impact of cranial irradiation on the growth of children with acute lymphocytic leukemia. Arch Pediatr Adolesc Med [Am J Dis Child] 1983;137:37-9.

9. Berry DH, Elders MJ, Crist W, Land V, Lui V, Sexaver AC, et al. Growth in children with acute lymphocytic leukemia: a Pediatric Oncology Group study. Med Pediatr Oncol 1983;11:39-45.

10. Kirk JA, Raghupathy P, Stevens MM, Cowell CT, Menser MA, Bergin M, et al. Growth failure and growth-hormone deficiency after treatment for acute lymphoblastic leukaemia. Lancet 1987;1:190-3,

11. Stacerski PJ, Lee PA, Blatt J, Finegold D, Brown D. Comparable effects of 1800- and 2400 rad (18- and 24-Gy) cranial irradiation on height and weight in children treated for acute lymphocytic leukemia. Arch Adolesc Pediatr Med [Am J Dis Child] 1987;141:550-2.

12. Clayton PE, Shalet SM, Morris-Jones PH, Price DA. Growth in children treated for acute lymphoblastic leukaemia. Lancet 1988;1:460-2.

13. Moëll C, Garwicz S, Màrky I, Mellander L, Karlberg J. Growth in children treated for acute lymphoblastic leukemia with and without prophylactic cranial irradiation. Acta Pediatr Scand 1988;77:688-92.

14. Katz JA, Chambers B, Everhart C, Marks JF, Buchanan GR. Linear growth in children with acute lymphoblastic leukemia treated without cranial irradiation. $\mathrm{J}$ Pediatr 1991;118:575-8.

15. Màrky I, Samuelson BO, Mellander L, Karlberg J. Longitudinal growth in children with non-Hodgkin's lymphoma and children with acute lymphoblastic leukemia: comparison between unirradiated and irradiated patients. Med Pediatr Oncol 1991;19:96-9.

16. Thun-Hohenstein L, Frisch H, Schuster E. Growth after radiotherapy and chemotherapy in children with leukemia or lymphoma. Horm Res 1992;37:91-5.

17. Olshan JS, Gubernick J, Packer RJ, D'Angio GJ, Goldwein JW, Willi M, et al. The effects of adjuvant chemotherapy on growth in children with medulloblastoma. Cancer 1992;70:2013-7.

18. Sklar C, Mertens A, Walter A, Mitchell D, Nesbit M, O'Leary M, et al. Final height alter treatment for childhood acute lymphoblastic leukemia: comparison of no cranial irradiation with 1800 and 2400 centigrays of cranial irradiation. J Pediatr 1993;123:59-64.

19. Brauner R, Fontoura M, Zucker JM, Devergie A, Souberbielle JC, Prevot-Saucet $\mathrm{C}$, et al. Growth and growth hormone secretion after bone marrow transplantation. Arch Dis Child 1993;68:45863. 
20. Caruso-Nicoletti M, Mancuso M, Spadaro G, Dibenedetto SP, DiCataldo A, Schiliró G. Growth and growth hormone in children during and after therapy for acute lymphoblastic leukaemia. Eur J Pediatr 1993;152:730-3.

21. Hokken-Koelega ACS, Van Doorn JWD, Hählen K, Stijnen T, De Muinck Keizer-Schrama SMPF, Drop SLS. Long-term effects of treatment for acute lymphoblastic leukemia with and without cranial irradiation on growth and puberty: a comparative study. Pediatr Res 1993;33:577-82.

22. Liesner RJ, Leiper AD, Hann IM, Chessells JM. Late effects of intensive treatment for acute myeloid leukemia and myelodysplasia in childhood. J Clin Oncol 1994;12:916-24.

23. Voorhess ML, Brecher ML, Glicksman AS, Jones 13, Harris M, Krischer J, et al. Hypothalamic-pituitary function of children with acute lymphocytic leukemia after three forms of central nervous system prophylaxis. Cancer 1986;57:128791.

24. Màrky I, Mellander L, Lannering B, Albertsson-Wikland K. A longitudinal study of growth and growth hormone secretion in children during treatment for acute lymphoblastic leukemia. Med Pediatr Oncol 1991;19:258-64.

25. Borgstrom B, Bolme P. Growth and growth hormone in children after bone marrow transplantation. Horm Res 1988;30:98-100.

26. Wingard JR, Plotnick LP, Freemer CS. Growth in children after bone marrow transplantation: busulfan plus cyclophosphamide versus cyclophosphamide plus total body irradiation. Blood 1992;79:106873.

27. Giri N, Davis EA, Vowels MR. Long-terco complications following bone marrow transplantation in children. J Pediatr Child Health 1993;29:201-5.

28. Rappaport R, Brauner R Growth and endocrine disorders secondary to cranial irradiation. Pediatr Res 1989;25:561-7.

29. Talvensaari KK, Lanning M, Paakko E, Tapanainen P, Knip M. Pituitary size assessed with magnetic resonance imaging as a measure of growth hormone secretion in long terco survivors of childhood cáncer. J Clin Endocrinol Metab 1994;79: 1122-7.

30. Shalet SM. Radiation and pituitary disfunction. N Engl J Med 1993;328:131-3.

31. Kornblith PL, Walker M. Chemotherapy for malignant gliomas. J Neurosurg 1988; 68:1-17.

32. Alba-Roth J, Losa M, Spiess Y, Schopohl J, Müller OA. Interaction of clonidine and GHRH on GH secretion in vivo and in vitro. Clin Endocrinol 1989;30:48591.

33. Chihara K, Kashio Y, Kita T, Okimura Y, Kaji H, Abe H, et al. L-Dopa stimulates release of hypothalamic growth hormonereleasing hormone in humans. J Clin Endocrino' Metabol 1986;62:466-73.

34. Kitajima N, Chihara K, Abe H, Okimura Y, Fujii Y, Sato M, et al. Effects of dopamine on immunoreactive growth hormone-releasing factor and somatostatin secretion from rat hypothalamic slices perfused in vitro. Endocrinology 1989;124:6976.

35. Müller EE. Neural control of somatrotopic function. Physiol Rev 1987;67:9621053.

36. Blacklay A, Grossman A, Ross RJM, Savage MO, Davies PSW, Plowman PN, et al. Cranial irradiation for cerebral and nasopharingeal tumours in children: evidence for reproduction of a hypothalamic defect in growth hormone release. J Endocrinol 1986;108:25-9. 
Table 1. Main chemotherapeutic agents used for each type of tumor

\begin{tabular}{|l|c|c|c|c|c|c|c|c|c|c|}
\hline Tumor & ADR & Act-D & Ara-C & Bleo & CDDP & CPA & DXM & DTIC & IFX & MTX \\
\hline Ewing sarcoma & + & + & - & + & - & + & - & - & + & + \\
\hline Hodgkin disease & + & - & - & + & - & - & - & + & - & - \\
\hline Non-Hodgkin disease & + & - & + & + & + & + & + & - & + & + \\
\hline Osteosarcoma & + & + & - & + & + & + & - & - & - & + \\
\hline Rhabdomyosarcoma & + & + & - & - & + & + & - & + & + & - \\
\hline Wilms tumor & + & + & - & - & + & + & - & - & + & - \\
\hline
\end{tabular}

Act-D, Actinomycin D; ADR, adriamycin; Ara-C, cytarabine; Bleo, bleomycin; CDDP, cisplatin; CPA, cyclophosphamide; DXM, dexamethasone; IFX, ifosfamide,;MTX, methotrexate;

\begin{tabular}{|l|c|c|c|c|c|c|}
\hline Tumor & Nitrog M. & Pred & Procarb & Vinbl & VCR & VP-16 \\
\hline Ewing sarcoma & - & - & - & - & + & - \\
\hline Hodgkin disease & + & + & + & + & + & - \\
\hline Non-Hodgkin disease & - & + & - & - & + & + \\
\hline Osteosarcoma & - & - & - & - & + & - \\
\hline Rhabdomyosarcoma & - & - & - & - & + & - \\
\hline Wilms tumor & - & - & - & - & + & - \\
\hline \\
Nitrog M, nitrogen mustard; Pred, prednisone; Procarb, procarbanize; \\
VCR, vincristine;Vinbl, vinblastine,VP-16, etoposide. \\
\hline
\end{tabular}


Table 2. Maximum peak and AUC of GH response to clonidine and GHRH in the prospective group (comparative statistical analysis)

\begin{tabular}{|c|c|c|c|c|c|c|c|c|}
\hline Patient N $^{\mathbf{0}}$ & Peak & AUC & Peak & AUC & Peak & AUC & Peak & AUC \\
\hline 1 & 11.0 & 98.2 & 21.0 & 209.8 & 1.1 & 12.4 & 5.6 & 52.2 \\
\hline 2 & 4.5 & 40.1 & 13.3 & 122.8 & 3.7 & 22.0 & 2.2 & 22.5 \\
\hline 3 & 6.1 & 45.4 & 13.1 & 63.0 & 6.3 & 32.3 & 4.1 & 41.0 \\
\hline 4 & ND & ND & 12.8 & 82.8 & 1.8 & 14.1 & 2.6 & 23.4 \\
\hline 5 & 32.0 & 200.7 & 5.2 & 46.9 & 7.8 & 55.0 & 5.9 & 58.8 \\
\hline 6 & 12.2 & 95.8 & 18.3 & 184.0 & 3.8 & 11.2 & 8.0 & 85.6 \\
\hline 7 & 10.2 & 75.1 & 10.7 & 53.4 & 7.2 & 56.3 & 11.2 & 41.3 \\
\hline 8 & 17.5 & 130.4 & ND & ND & 3.7 & 29.5 & 16.7 & 151.2 \\
\hline 9 & 10.5 & 79.5 & 11.6 & 79.8 & 9.0 & 57.0 & 10.1 & 78.0 \\
\hline 10 & 5.2 & 31.6 & 10.5 & 87.2 & 4.3 & 47.5 & 2.4 & 27.0 \\
\hline 11 & 12.1 & 88.6 & 12.4 & 97.3 & 2.6 & 20.2 & 10.9 & 34.0 \\
\hline 12 & 16.9 & 109.6 & 12.1 & 85.9 & 16.2 & 81.2 & 15.9 & 136.9 \\
\hline Mean+SD & $12.6 \pm 7.7$ & $90.4 \pm 47.5$ & $12.8 \pm 4.1$ & $101.1 \pm 52.0$ & $5.6 \pm 4.1 *$ & $36.5 \pm 22.4 *$ & $7.9 \pm 4.9 \dagger$ & $62.6 \pm 43.1 \dagger$ \\
\hline
\end{tabular}

AUC, Area under curve (in nanograms per milliliter per 120 minutes); GH, growth hormone; GHRH, growth hormone-releasing hormone; peak, maximum peak (in nanograms per milliliter); ND, not done. ${ }^{*} p<0.01$ after treatment versus before treatment.

$\dagger \mathrm{p}<0.05$ after treatment versus before treatment.

Table 3. Comparative statistical analysis of measures of GH response alter stimulus with clonidine, L-dopa, and GHRH in GH-deficient and non-GH-deficient patients

\begin{tabular}{|c|c|c|c|}
\hline & Clonidine & L-Dopa & GHRH \\
\hline \multicolumn{4}{|l|}{ Non-GHD } \\
\hline Peak (ng/ml) & $7.4 \pm 4.3$ & $16.3 \pm 8.8^{t}$ & $16.4 \pm 7.2^{t}$ \\
\hline $\mathrm{AUC}(\mathrm{nc} / \mathrm{ml} / 120 \mathrm{~min})$ & $55.4 \pm 33.2$ & $11.93 \pm 76.3^{t}$ & $129.8 \pm 65.4^{t}$ \\
\hline Response (\%) & 27 & $84^{t}$ & 96 \\
\hline \multicolumn{4}{|l|}{ GHD } \\
\hline Peak (ng/ml) & $3.9 \pm 2.1$ & $4.6 \pm 2.2^{\S}$ & $4.9 \pm 2.3^{\S}$ \\
\hline AUC (nc/ml/120 min) & $26.4 \pm 15.1$ & $38.9 \pm 21.2 *$ & $45.0 \pm 21.5^{\dagger}$ \\
\hline Response $(\%)$ & 0 & $0^{\S}$ & $0^{\S}$ \\
\hline \multicolumn{4}{|c|}{$\begin{array}{l}\text { Values (except percentage of response) are expressed as mean } \pm \mathrm{SD} \text {. } \\
\text { AUC, Area under curve (in nanograms per milliliter per } 120 \text { minutes); GH, growth } \\
\text { hormone; GHRH, growth hormone-releasing hormone; peak, maximum peak. } \\
{ }^{*} p<0.05 \text { compared with clonidine. } \\
{ }^{\dagger} p<0.01 \text { compared with clonidine. } \\
{ }^{t}<<0.001 \text { compared with clonidine. } \\
{ }^{\$} \text { Not significant compared with clonidine. }\end{array}$} \\
\hline
\end{tabular}


Table 4. Height and growth rate in GH-deficient and non-GH-deficient patients

\begin{tabular}{|l|c|c|c|c|}
\hline Time of measurement & Height SDS & p & $\begin{array}{c}\text { Growth rate } \\
\text { SDS }\end{array}$ & p \\
\hline Diagnosis & & & & \\
\hline GHD group & $0.23 \pm 0.11$ & & & \\
\hline Non-GHD group & $0.16 \pm 010$ & & & \\
\hline End of therapy & & & & \\
\hline GHD group & $-0.28 \pm 0.15$ & 0.04 & $0.13 \pm 0.07$ & \\
\hline Non-GHD group & $-0.14 \pm 0.11$ & & $0.22 \pm 0.18$ & \\
\hline 30 Months' follow-up & & & & \\
\hline GHD group & $-0.4 \pm 0.29$ & $0.03(0.02)^{*}$ & $-0.27 \pm 0.19$ & 0.03 \\
\hline Non-GHD group & $-0.24 \pm 0.16$ & & $-0.16 \pm 0.12$ & \\
\hline
\end{tabular}

Values (except $p$ value) are expressed as mean \pm SD.

$\mathrm{GH}$, Growth hormone; GHD, growth hormone deficiency; SDS, standard deviation score.

*Differences between diagnosis and follow-up. 


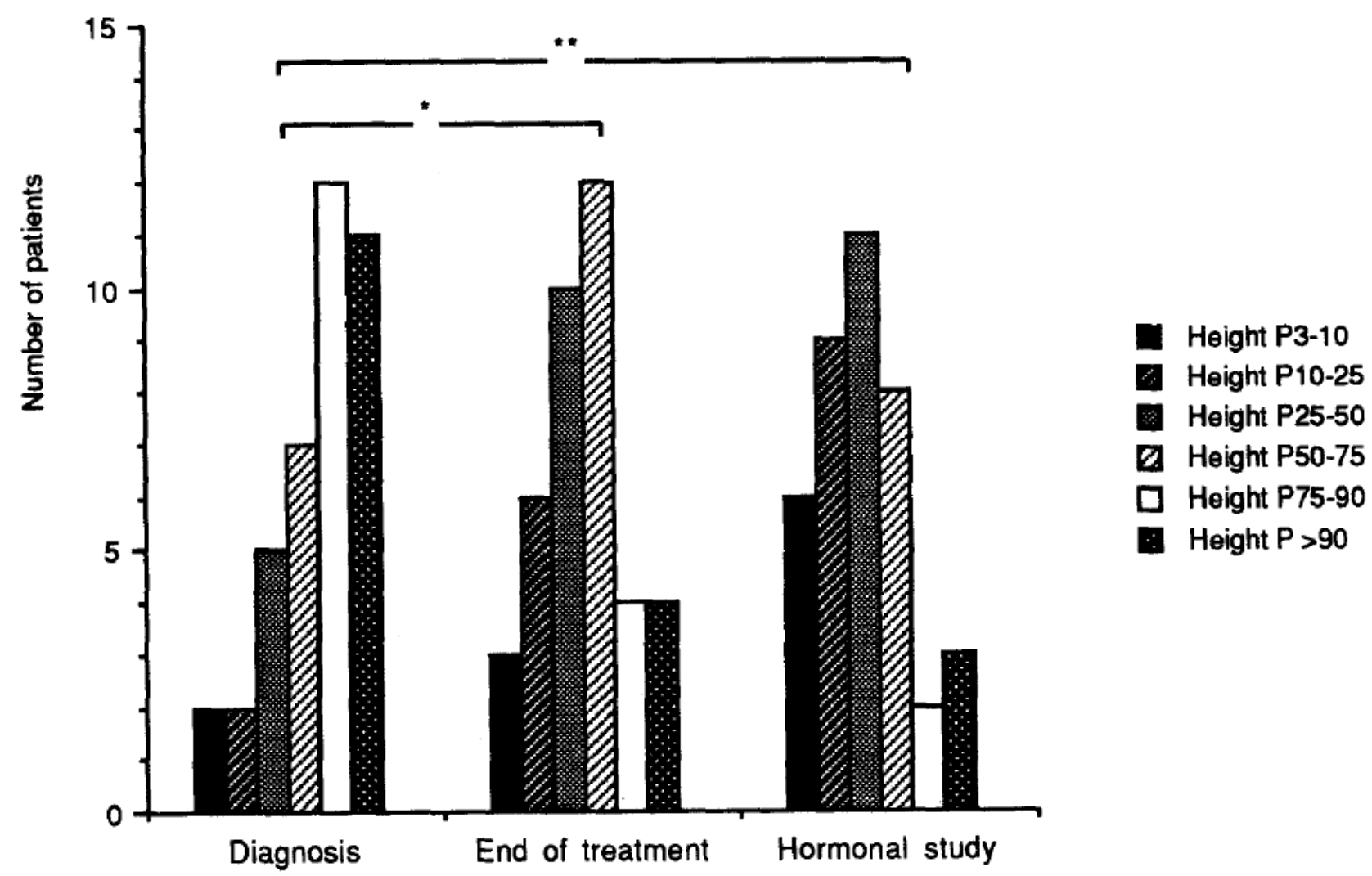

Figure. Evolution of height percentiles (excluding patients with adult bone age and those who received radiotherapy to the spinal column) at diagnosis, end of treatment, and hormonal study performance $(n=39)$. Height $P$, Height percentile. ${ }^{*} p<0.05$; $* * \mathrm{p}<0.01$. 